\title{
Are Prostate Carcinoma Clinical Stages T1c and T2 Similar?
}

\author{
Athanase Billis, Luis A. Magna, Isabela C. Watanabe, Matheus V. Costa, Gilliatt H. Telles, \\ Ubirajara Ferreira
}

\author{
Department of Anatomic Pathology (AB, ICW, MVC, GHT), Department of Medical Genetics and \\ Biostatistics (LAM), and Department of Urology (UF), School of Medicine, State University of \\ Campinas (Unicamp), Campinas, SP, Brazil
}

\begin{abstract}
Purpose: A recent study has found that PSA recurrence rate for clinical T1c tumors is similar to T2 tumors, indicating a need for further refinement of clinical staging system. To test this finding we compared clinicopathologic characteristics and the time to PSA progression following radical retropubic prostatectomy of patients with clinical stage T1c tumors to those with stage $\mathrm{T} 2, \mathrm{~T} 2 \mathrm{a}$ or $\mathrm{T} 2 \mathrm{~b}$ tumors.

Materials and Methods: From a total of 186 consecutive patients submitted to prostatectomy, $33.52 \%$ had clinical stage T1c tumors, $45.45 \%$ stage T2a tumors and $21.02 \%$ stage T2b tumors. The variables studied were age, preoperative PSA, prostate weight, Gleason score, tumor extent, positive surgical margins, extraprostatic extension (pT3a), seminal vesicle invasion (pT3b), and time to PSA progression. Tumor extent was evaluated by a point-count method.

Results: Patients with clinical stage T1c were younger and had the lowest mean preoperative PSA. In the surgical specimen, they had higher frequency of Gleason score $<7$ and more organ confined cancer. In $40.54 \%$ of the patients with clinical stage T2b tumors, there was extraprostatic extension (pT3a). During the study period, 54 patients (30.68\%) developed a biochemical progression. Kaplan-Meier product-limit analysis revealed no significant difference in the time to PSA progression between men with clinical stage T1c versus clinical stage T2 $(p=0.7959)$, T2a $(p=0.6060)$ or T2b $(p=0.2941)$ as well as between men with clinical stage $\mathrm{T} 2 \mathrm{a}$ versus stage $\mathrm{T} 2 \mathrm{~b}(\mathrm{p}=0.0994)$.

Conclusion: Clinicopathological features are not similar considering clinical stage T1c versus clinical stages $\mathrm{T} 2$, $\mathrm{T} 2 \mathrm{a}$ or T2b.
\end{abstract}

Key words: prostatic neoplasms; pathology; neoplasm staging; prostate-specific antigen

Int Braz J Urol. 2006; 32: 165-71

\section{INTRODUCTION}

A recent study (1) has found that PSA recurrence rate for clinical $\mathrm{T} 1 \mathrm{c}$ tumors is similar to $\mathrm{T} 2$ tumors, indicating a need for further refinement of clinical staging system. To test this finding we compared clinicopathologic characteristics and the time to PSA progression following radical prostatectomy of patients with clinical $\mathrm{T} 1 \mathrm{c}$ tumors to those with $\mathrm{T} 2$ tumors as well as subclassifying stage $\mathrm{T} 2$ into stages $\mathrm{T} 2 \mathrm{a}$ and $\mathrm{T} 2 \mathrm{~b}$.

\section{MATERIAL AND METHODS}

The study was done on 59 patients with clinical stage T1c tumors and 127 patients with clinical stage $\mathrm{T} 2$ tumors submitted to radical retropubic pros- 
tatectomy from January 1997 to July 2004 in our Institution. The variables studied were age, preoperative PSA, prostate weight and pathologic findings in the surgical specimens: Gleason score, tumor extent, positive surgical margins, extraprostatic extension (pT3a), and seminal vesicle invasion (pT3b). Time to biochemical progression following surgery was studied comparing the groups: $\mathrm{T} 1 \mathrm{c}$ versus $\mathrm{T} 2, \mathrm{~T} 1 \mathrm{c}$ versus $\mathrm{T} 2 \mathrm{a}, \mathrm{T} 1 \mathrm{c}$ versus $\mathrm{T} 2 \mathrm{~b}$, and $\mathrm{T} 2 \mathrm{a}$ versus $\mathrm{T} 2 \mathrm{~b}$.

The surgical specimen previously fixed was weighed, measured and the entire surface inked. The bladder neck and apical margins were amputated. From each cone-shaped amputated margin, 8 fragments were processed through perpendicular sections relative to the margins. The rest of the prostate was serially cut in transverse sections at 3 to $5 \mathrm{~mm}$ intervals. The prostate slices were subdivided into quadrants and labeled to allow for reconstruction as wholemount sections.

Blocks were embedded in paraffin, cut at 6 $\mu \mathrm{m}$, and one section from each block was stained with hematoxylin and eosin. Presence of adenocarcinoma was diagnosed according to the criteria of Mostofi and Price (2). The diagnosis was based on invasion or architectural disturbance. Histological grading was performed according to the Gleason system (3). Prostatic carcinomas with final score $<7$ were considered low-intermediate grade; and, with final score $\geq$ 7 were considered high-grade (4). Extraprostatic extension was diagnosed according to Bostwick \& Montironi (5), whenever cancer was seen in adipose tissue, and corresponds to pT3a in the TNM staging system (6). Seminal vesicle invasion was defined as an invasion of the muscular wall, as described by Epstein et al. (7), corresponding to pT3b in the TNM staging system.

Tumor extent was estimated by use of a pointcount method (8). Drawn on a sheet of paper, each quadrant of the whole mount sections contained 8 equidistant points. During the microscopic examination of the slides, the tumor area was drawn on the correspondent quadrant seen on the paper. At the end of the examination the amount of positive points represented an estimate of the tumor extent.

The 59 patients with stage T1c had clinically unapparent tumor not palpable or visible by imaging identified by needle biopsy. The 127 patients with clinical stage $\mathrm{T} 2$ had tumor confined within the prostate; 80 had stage T2a (tumor involving one lobe) and 37 had stage T2b (tumor involving both lobes). In 10 patients there was no information regarding subclassification of clinical stage T2.

Biochemical progression was defined as PSA $\geq 0.4 \mathrm{ng} / \mathrm{mL}$. From January 1997 to July 2005, 54 patients $(30.68 \%)$ developed a biochemical progression. The mean and median follow-up for these patients was 24.74 and 16 months, respectively (range 2 to 89 months).

The data were analyzed using the MannWhitney test for comparison of independent samples and Fisher's exact test for evaluating differences between proportions. Time to PSA progression was studied using the Kaplan-Meier product-limit analysis; the comparison between the groups was done using the log-rank test. For the analysis of time to biochemical progression, 18 patients without tests for PSA level following radical prostatectomy were excluded. The mean and median follow-up for 122 men without biochemical progression (censored patients) was 33.50 and 30.50 months, respectively (range 3 to 94 months). P value $<0.05$ was considered statistically significant. All statistical analyses were performed using Statistica 5.5 software (StatSoft, Inc., Tulsa, OK, USA).

\section{RESULTS}

Table-1 compares clinicopathologic features between 59 patients with stage T1c and 127 patients with stage $\mathrm{T} 2$. There were no statistically significant differences related to age $(\mathrm{p}=0.0788)$, preoperative PSA $(p=0.3791)$, prostate weight $(p=0.6301)$, tumor extent $(\mathrm{p}=0.1857)$, positive surgical margins ( $\mathrm{p}$ $=0.3163)$, extraprostatic extension $(\mathrm{p}=0.1020)$ and seminal vesicle invasion $(p=0.2481)$. There was a statistically significant higher number of patients with Gleason score $\geq 7$ in stage $\mathrm{T} 2(\mathrm{p}=0.0212)$.

Table-2 compares clinicopathologic features between 59 patients with stage T1c and 80 patients with stage T2a. There were no statistically significant differences related to preoperative PSA ( $p=$ $0.8068)$, prostate weight $(p=0.4777)$, Gleason score 
Table 1 - Clinicopathologic features of men undergoing radical prostatectomy, by clinical stage.

\begin{tabular}{|c|c|c|c|}
\hline Characteristic & Clinical Stage T1c (\%) & Clinical Stage T2 (\%) & p Value \\
\hline Number of patients & $59(31.72)$ & $127(68.28)$ & \\
\hline \multicolumn{4}{|l|}{ Age } \\
\hline Mean \pm SD & $61.96 \pm 7.17$ & $64.07 \pm 5.91$ & $0.0788^{(1)}$ \\
\hline \multicolumn{4}{|l|}{ Preoperative PSA (ng/mL) } \\
\hline Mean \pm SD & $9.32 \pm 4.04$ & $10.89 \pm 7.29$ & $0.3791^{(1)}$ \\
\hline Median & 7.8 & 9.12 & \\
\hline \multicolumn{4}{|l|}{ Prostate weight (g) } \\
\hline Mean \pm SD & $37.77 \pm 14.52$ & $39.28 \pm 16.37$ & $0.6301^{(1)}$ \\
\hline Median & 35 & 36 & \\
\hline \multicolumn{4}{|l|}{ Gleason score } \\
\hline$<7$ & $28(47.46)$ & $37(29.60)$ & $0.0212^{(2)}$ \\
\hline$\geq 7$ & $31(52.54)$ & $88(70.40)$ & \\
\hline \multicolumn{4}{|l|}{ Tumor extent } \\
\hline Mean \pm SD & $33.89 \pm 34.77$ & $39.75 \pm 39.46$ & \\
\hline Median & 25 & 29 & $0.1857^{(1)}$ \\
\hline Positive surgical margins & $23(38.98)$ & $39(30.70)$ & $0.3163^{(2)}$ \\
\hline Extraprostatic extension (pT3a) & $10(16.94)$ & $37(29.13)$ & $0.1020^{(2)}$ \\
\hline Seminal vesicle invasion (pT3b) & $5(8.47)$ & $20(15.74)$ & $0.2481^{(2)}$ \\
\hline
\end{tabular}

SD = standard deviation; ${ }^{(1)}$ Mann-Whitney; ${ }^{(2)}$ Fisher exact-test.

Table 2 - Clinicopathologic features of men undergoing radical prostatectomy, by clinical stage T1c and stage T2a.

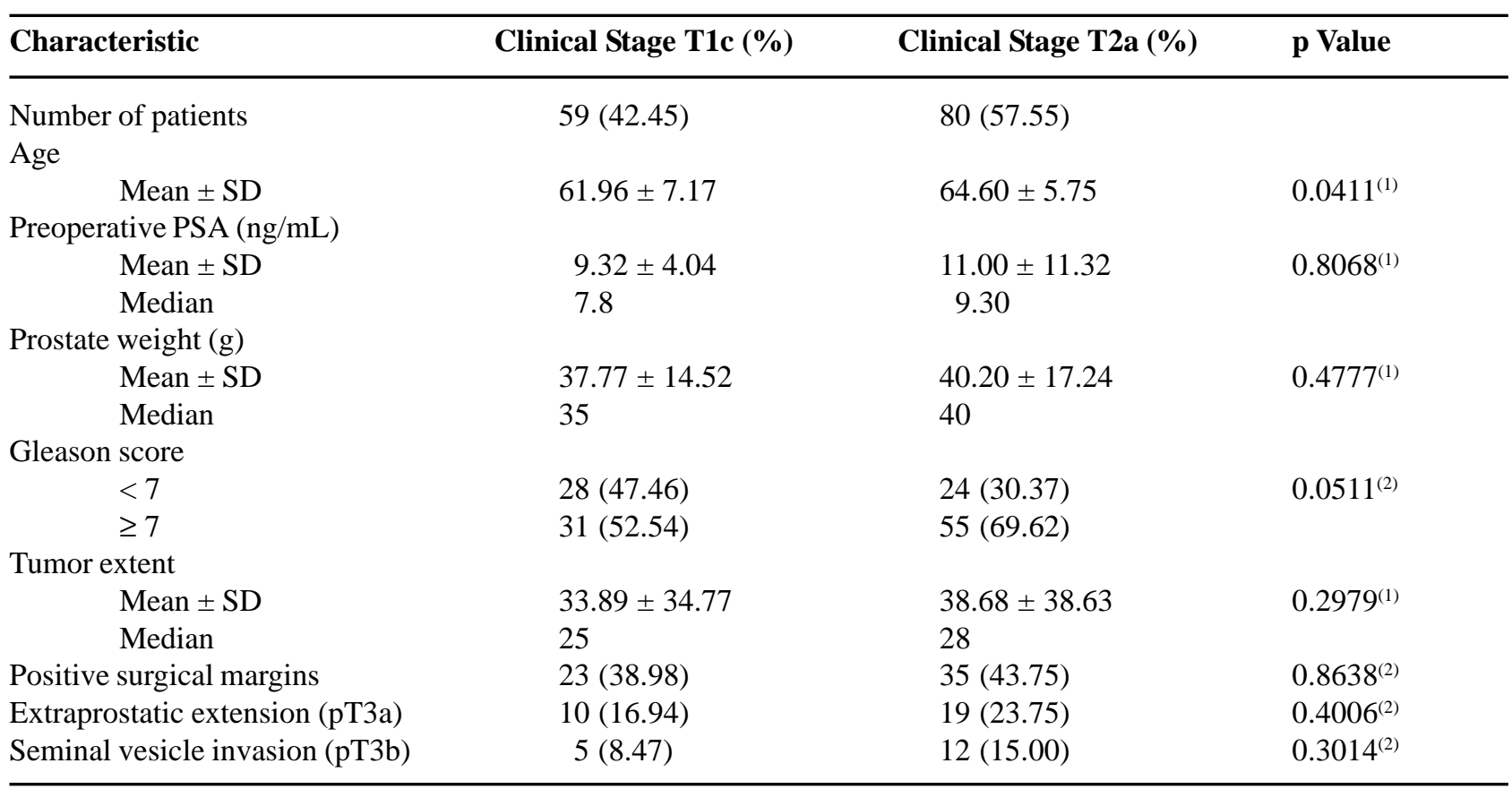

SD = standard deviation; ${ }^{(1)}$ Mann-Whitney; ${ }^{(2)}$ Fisher exact-test. 
$(p=0.0511)$, tumor extent $(p=0.2979)$, positive surgical margins $(\mathrm{p}=0.8638)$, extraprostatic extension $(\mathrm{p}=0.4006)$ and seminal vesicle invasion $(\mathrm{p}=$ 0.3014). Patients with clinical T2a tumors were significantly older than patients with stage T1c cancer $(\mathrm{p}=0.0411)$.

Table-3 compares clinicopathologic features between 59 patients with stage T1c and 37 patients with stage T2b. There were no statistically significant differences related to age $(\mathrm{p}=0.6693)$, preoperative PSA $(p=0.0616)$, prostate weight $(p=0.8185)$, Gleason score $(p=0.1336)$, tumor extent $(p=0.0948)$, positive surgical margins $(\mathrm{p}=0.6756)$, and seminal vesicle invasion $(\mathrm{p}=0.3264)$. There was a statistically significant higher number of patients with clinical stage T2b showing extraprostatic extension (pT3a) in the surgical specimen $(\mathrm{p}=0.0161)$.

Figure-1 shows the time to PSA progression using the Kaplan-Meier product-limit analysis. There was no statistical significance between patients with stage $\mathrm{T} 1 \mathrm{c}$ versus $\mathrm{T} 2(\mathrm{p}=0.7959)$.

Figure-2 shows the time to PSA progression using the Kaplan-Meier product-limit analysis.
There was no statistical significance between patients with stage $\mathrm{T} 1 \mathrm{c}$ versus $\mathrm{T} 2 \mathrm{a}(\mathrm{p}=0.6060)$ and $\mathrm{T} 1 \mathrm{c}$ versus $\mathrm{T} 2 \mathrm{~b}(\mathrm{p}=0.2941)$ as well as between patients with clinical stage $\mathrm{T} 2 \mathrm{~b}$ versus stage $\mathrm{T} 2 \mathrm{a}(\mathrm{p}$ $=0.0994$ ).

\section{COMMENTS}

The TNM staging system (6) places men with tumors detected because of elevated prostate-specific antigen in the T1c group and those with palpable nodule confined within the prostate in stage T2. The latter is subclassified into stage T2a (tumor involving one lobe) and stage T2b (tumor involving both lobes).

In a recent study, Armatys et al. (1) found that patients with clinical stage $\mathrm{T} 2$ tumors have higher Gleason score and final pathologic stage compared to those tumors detected because of elevated serum PSA (T1c). In our series, there was a statistically significant higher number of patients with Gleason score $\geq 7$ in clinical stage $\mathrm{T} 2$, however, there was no difference regarding pathologic stage. Armatys et al. (1) suggested a need for further refinement of clinical

Table 3 - Clinicopathologic features of men undergoing radical prostatectomy, by clinical stage T1c and T2b.

\begin{tabular}{lccc}
\hline Characteristic & Clinical Stage T1c (\%) & Clinical Stage T2b (\%) & p Value \\
\hline $\begin{array}{l}\text { Number of patients } \\
\text { Age } \quad 59(61.46)\end{array}$ & $37(38.54)$ & \\
$\quad$ Mean \pm SD & $61.96 \pm 7.17$ & $62.76 \pm 6.58$ & $0.6693^{(1)}$ \\
Preoperative PSA (ng/mL) & & & \\
$\quad$ Mean \pm SD & $9.32 \pm 4.04$ & $13.44 \pm 10.07$ & $0.0616^{(1)}$ \\
$\quad$ Median & 7.8 & 10.00 & \\
Prostate weight (g) & & & \\
$\quad$ Mean \pm SD & $37.77 \pm 14.52$ & $37.21 \pm 14.88$ & $0.8185^{(1)}$ \\
$\quad$ Median & 35 & 30 & \\
Gleason score & $28(47.46)$ & $11(30.56)$ & $0.1336^{(2)}$ \\
$\quad 7$ & $31(52.54)$ & $25(69.44)$ & \\
$\quad 7$ & $33.89 \pm 34.77$ & $46.52 \pm 44.99$ & $0.0948^{(1)}$ \\
Tumor extent & 25 & 34 & \\
$\quad$ Mean \pm SD & $23(38.98)$ & $15(40.55)$ & $0.6756^{(2)}$ \\
$\quad$ Median & $10(16.94)$ & $6(16.21)$ & $0.0161^{(2)}$ \\
Positive surgical margins & $5(8.47)$ & $0.3264^{(2)}$ \\
Extraprostatic extension (pT3a) & Seminal vesicle invasion (pT3b) &
\end{tabular}

$S D=$ standard deviation; ${ }^{(1)}$ Mann-Whitney; ${ }^{(2)}$ Fisher exact-test. 
Cumulative Proportion Surviving (Kaplan - Meier)

Complete + Censored

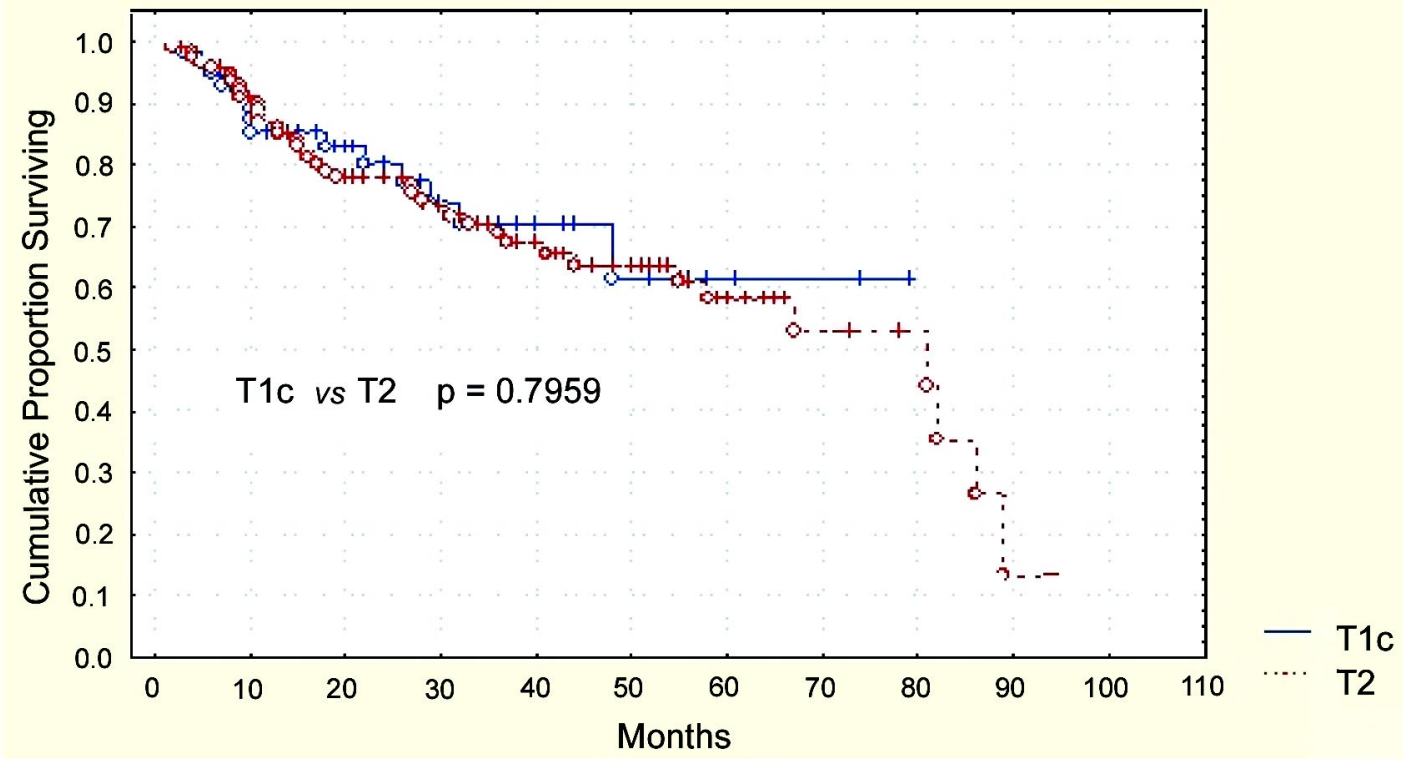

Figure 1 - Time to PSA progression according to clinical stages T1c and T2. Kaplan-Meier product-limit analysis.

\section{Cumulative Proportion Surviving (Kaplan - Meier) \\ - Complete + Censored}

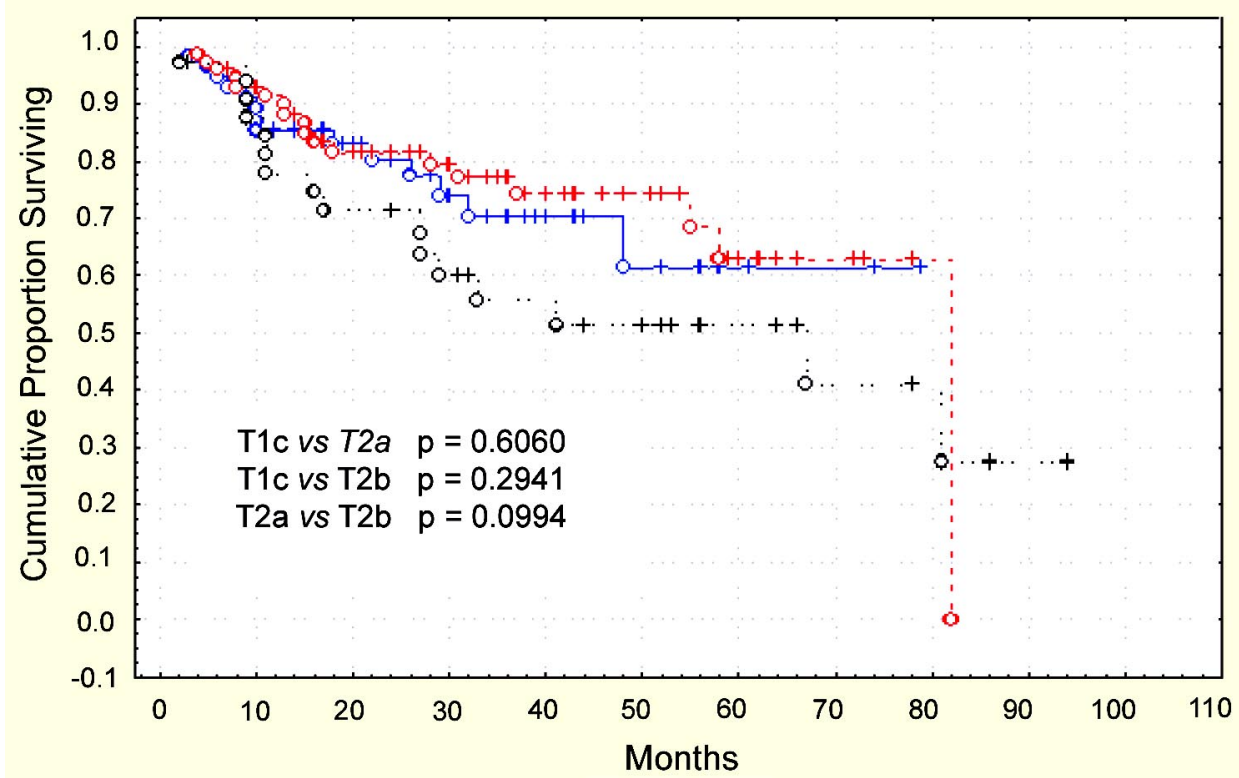

Figure 2 - Time to PSA progression according to clinical stages T1c, T2a and T2b. Kaplan-Meier product-limit analysis. 
staging system because the PSA recurrence rate for T1c tumors was similar to cT2 tumors. This finding is similar to our study; however, the authors did not considered the subclassification of stage $\mathrm{T} 2$ into stages $\mathrm{T} 2 \mathrm{a}$ and $\mathrm{T} 2 \mathrm{~b}$.

Jack et al. (9) compared tumor location and pathological parameters in the radical prostatectomy specimens of stages T1c versus T2 cases in a 3-year period. Prostate specific antigen detected stage T1c tumors had a lower grade, stage and volume than stage T2 tumors during the same period. Lower tumor grade in stage T1c cases were due at least in part to the increased detection of Gleason pattern 2 containing transition zone tumors. The authors did not study the PSA progression rate for T1c and cT2 tumors as well as did not subclassified clinical stage $\mathrm{T} 2$.

Furuya et al. (10), in order to examine the characteristics of men with nonpalpable prostate cancer (T1c cancer) in Japan, compared patients treated with radical prostatectomy with those with palpable (T2) cancer. Prostate-specific antigen level in patients with $\mathrm{T} 2 \mathrm{~b}$ disease was significantly higher than those with T1c and T2a tumors. At the time of radical prostatectomy, $78 \%, 71 \%$ and $31 \%$ of patients with T1c, $\mathrm{T} 2 \mathrm{a}$, and $\mathrm{T} 2 \mathrm{~b}$, respectively, had organ-confined disease. T1c cancers were clinically significant and clinicopathological features of T1c tumors were similar to T2a tumors. In our study, the mean preoperative PSA was 9.32, 11.00 and 13.44 in patients with stage T1c, T2a and T2b, respectively. Extraprostatic extension in the surgical specimen (pT3a) was found in $16.94 \%, 23.75 \%$ and $40.54 \%$ of the patients in stage T1c, T2a and T2b, respectively. These clinicopathologic findings are in accordance with Furuya et al. The authors did not study time to biochemical progression following surgery.

The definition of the serum PSA level for biochemical progression is controversial and varies from $0.2 \mathrm{ng} / \mathrm{mL}$ to $0.6 \mathrm{ng} / \mathrm{mL}$ in the literature (11-15). We considered as biochemical progression serum PSA level of $0.4 \mathrm{ng} / \mathrm{mL}$. Using the Kaplan-Meier productlimit analysis, there was no statistically significant difference in the time to PSA progression between patients with clinical stage T1c versus stage $\mathrm{T} 2(\mathrm{p}=$ $0.7959), T 1 c$ versus $T 2 a(p=0.6060), T 1 c$ versus $T 2 b$ $(\mathrm{p}=0.2941)$ as well as between patients with clinical stage T2b versus stage T2a $(p=0.0994)$.

Ramos et al. (16) compared clinicopathological features, and cancer recurrence and survival rates in men with stage $\mathrm{T} 1 \mathrm{c}$ versus $\mathrm{T} 2 \mathrm{a}$ or $\mathrm{T} 2 \mathrm{~b}$ prostate cancer. The 5-year recurrence-free survival was similar for T1c versus T2a, and higher versus T2b cancers. Clinical stage was T1c in 39\%, T2a in $22 \%$ and $\mathrm{T} 2 \mathrm{~b}$ in $39 \%$ of their patients; in our study, was $33.52 \%, 45.45 \%$ and $21.02 \%$, respectively. Mean patient age was younger for the clinical stage T1c group (61 years) in their study as well as in ours (61 years).

Ghavamian et al. (17) compared clinicopathologic findings and PSA progression following radical retropubic prostatectomy in patients with clinical stage T1c, T2a or T2b cancer. Survival rates for T1c tumors were similar to T2a lesions, but significantly better than T2b lesions. Clinical T1c tumors were more likely to be organ confined and with a Gleason score less than 7. Considering tumor volume, T1c tumors were comparable to T2a lesions. Our findings showed that patients with stage T1c were more likely to have organ confined, Gleason score $<7$ and less extensive tumors. Using a point-count method for estimating tumor extent the mean was $33.89,38.68$ and 46.52 positive points for stages T1c, T2a and T2b, respectively.

\section{CONCLUSIONS}

Clinicopathological features are not similar considering clinical stage T1c versus clinical stages T2, T2a or T2b. A statistically higher number of patients have Gleason score $\geq 7$ in stage T2; are older in stage T2a; and, are not organ confined in stage T2b. Time to PSA progression following radical prostatectomy is similar between men in clinical stage T1c versus stages $\mathrm{T} 2, \mathrm{~T} 2 \mathrm{a}$ or T2b as well as between patients with clinical stage $\mathrm{T} 2 \mathrm{~b}$ versus stage $\mathrm{T} 2 \mathrm{a}$.

\section{CONFLICT OF INTEREST}

None declared. 


\section{REFERENCES}

1. Armatys A, Koch MO, Bihrle R, Gardner TA, Eble JN, Patel NB, et al.: A clinicopathologic comparison of clinical stages T1c versus T2 prostate adenocarcinoma: Lack of differences in PSA recurrence, Mod Pathol. 2004; 17(suppl 1):138A.

2. Mostofi, FK, Price EB Jr: Tumors of the Male Genital System, Atlas of Tumor Pathology, Second Series, Fascicle 8. Washington DC, Armed Forces Institute of Pathology. 1973; pp. 202-17.

3. Gleason DF, Mellinger GT: Prediction of prognosis for prostatic adenocarcinoma by combined histological grading and clinical staging. J Urol. 1974; 111: 5864.

4. Gleason DF: Histologic grading of prostate cancer: a perspective. Hum Pathol. 1992; 23: 273-9.

5. Bostwick DG, Montironi R: Evaluating radical prostatectomy specimens: therapeutic and prognostic importance. Virchows Arch. 1997; 430: 1-16.

6. International Union Against Cancer: Prostate. In: Sobin LH, Wittekind Ch. (eds.), TNM Classification of Malignant Tumours, 6th ed. New York, Wiley-Liss. 1997; pp. 170-3.

7. Epstein JI, Carmichael M, Walsh PC: Adenocarcinoma of the prostate invading the seminal vesicle: definition and relation of tumor volume, grade and margins of resection to prognosis. J Urol. 1993; 149: 1040-5.

8. Billis A, Magna LA, Ferreira U: Correlation between tumor extent in radical prostatectomies and preoperative PSA, histological grade, surgical margins, and extraprostatic extension: application of a new practical method for tumor extent evaluation. Int Braz J Urol. 2003; 29: 113-9; discussion 120.

9. Jack GS, Cookson MS, Coffey CS, Vader V, Roberts RL, Chang SS, et al.: Pathological parameters of radical prostatectomy for clinical stages T1c versus T2 prostate adenocarcinoma: decreased pathological stage and increased detection of transition zone tumors. J Urol. 2002; 168: 519-24.

10. Furuya Y, Ohta S, Sato N, Kotake T, Masai M: Comparison of T1c versus $\mathrm{T} 2$ prostate cancers in Japanese patients undergoing radical prostatectomy. Int Urol Nephrol. 2002; 33: 73-6.

11. Amling CL, Bergstralh EJ, Blute ML, Slezak JM, Zincke H: Defining prostate specific antigen progression after radical prostatectomy: what is the most appropriate cut point? J Urol. 2001; 165: 1146-51.

12. Han M, Partin AW, Zahurak M, Piantadosi S, Epstein JI, Walsh PC: Biochemical (prostate specific antigen) recurrence probability following radical prostatectomy for clinically localized prostate cancer. J Urol. 2003; 169: 517-23.

13. Sofer M, Savoie M, Kim SS, Civantos F, Soloway MS: Biochemical and pathological predictors of the recurrence of prostatic adenocarcinoma with seminal vesicle invasion. J Urol. 2003; 169: 153-6.

14. Moul JW, Douglas TH, McCarthy WF, McLeod DG: Black race is an adverse prognostic factor for prostate cancer recurrence following radical prostatectomy in an equal access health care setting. J Urol. 1996; 155: 1667-73.

15. Andersson J, Ekman P, Egevad L, Hellstrom M: Relatively high risk of treatment failure after prostatectomy: tumour grade, histopathological stage and the preoperative serum PSA level are key prognosticators. Scand J Urol Nephrol. 2001; 35: 453-8.

16. Ramos CG, Carvalhal GF, Smith DS, Mager DE, Catalona WJ: Clinical and pathological characteristics, and recurrence rates of stage T1c versus T2a or T2b prostate cancer. J Urol. 1999; 161: 1525-9.

17. Ghavamian R, Blute ML, Bergstralh EJ, Slezak J, Zincke H: Comparison of clinically nonpalpable prostate-specific antigen-detected (cT1c) versus palpable (cT2) prostate cancers in patients undergoing radical retropubic prostatectomy. Urology. 1999; 54: 105-10.

\author{
Correspondence address: \\ Dr. Athanase Billis \\ Dept. de Anatomia Patológica, UNICAMP \\ Caixa Postal 6111 \\ Campinas, SP, 13084-971, Brazil \\ E-mail: athanase@fcm.unicamp.br
}

